\section{“SE PERDER E DER SHOW, VAI LUTAR DE NOVO!" MMA E O CONCEITO DE ESPORTE}

"IF YOU LOSE AND FIGHT HARD, YOU'LL FIGHT AGAIN!" - MMA AND

THE CONCEPT OF SPORT Q

"¡SI PIERDES, PERO DAS ESPECTÁCULO, LUCHARÁS DE NUEVO!”

MMA Y EL CONCEPTO DE DEPORTE C

doi' https://doi.org/10.22456/1982-8918.108259

Flávio Py Mariante Neto*<flaviomariante@hotmail.com>

Daniel Giordani Vasques** <dgvasques@hotmail.com>

Marco Paulo Stigger** <stigger.mp@gmail.com>

\footnotetext{
*Universidade Luterana do Brasil (ULBRA). Canoas, RS, Brasil.

**Universidade Federal do Rio Grande do Sul. Porto Alegre, RS, Brasil.
}

Resumo: A caracterização do esporte moderno elenca elementos que o distinguem de outras práticas corporais. As artes marciais mistas (MMA) são frequentemente compreendidas como uma modalidade esportivizada a partir de mudanças que visaram ao regramento e à diminuição da violência. Este estudo objetivou analisar o MMA a partir daquilo que o distingue dos outros esportes com base no conceito de esportivização proposto por Elias e Dunning. A metodologia, etnográfica, utilizou a observação participante em uma academia de MMA e em eventos de luta, da produção de diários de campo e de entrevistas. Três categorias empíricoanalíticas foram construídas para análise de elementos do MMA (o "dono do evento"; o espetáculo acima da vitória; e a violência como espetáculo), as quais sugerem debates com as noções de vitória, institucionalização, pertencimento e violência. Indicou-se a importância de um alargamento do conceito de esporte para compreender o MMA.

Palavras chave: Esportes. Violência. Institucionalização. Sociologia.
Recebido em: 08 out. 2020 Aprovado em: 07 abr. 2021 Publicado em: 09 jun. 2021

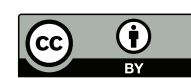

Este é um artigo publicado sob a licença Creative Commons Atribuição 4.0 Internacional (CC BY 4.0).

eISSN: $1982-8918$ 


\section{INTRODUÇÃO}

A caracterização do esporte e de seus processos de transformação vem sendo objeto de análise de estudos sociológicos desde meados do século passado. Alguns elementos são compartilhados entre os autores da área, como a noção de que se trata de fenômeno típico da modernidade, de que as modalidades foram modificadas por um processo de transformação da sua estrutura e de seus sentidos, e de que o esporte reflete em alguma medida aspectos da estrutura social vigente. Tais análises proporcionam reflexões sobre as características concernentes ao esporte e acabam por definir elementos que identificam esse fenômeno e, por sua vez, distanciam-no de outras práticas sociais.

Os estudos de Bourdieu $(1983,1990,1997)$ sobre o esporte caracterizamno como fenômeno moderno caracterizado em práticas institucionalizadas em federações com relativa autonomia desenvolvidas a partir do associativismo esportivo. Hobsbawm (2012), por sua parte, analisou a invenção e a transformação do esporte a partir da institucionalização. Em busca de identidade, surgem nas universidades os clubes de alunos, ex-alunos ou alunos antigos que jogam entre instituições universitárias. Dois fenômenos identitários são associados à função do esporte: a demonstração de laços que unem os habitantes de determinado local e os campeonatos internacionais, para sublinhar a superioridade das nações. Guttmann (1978), por sua vez, elenca características distintivas do esporte frente a práticas corporais comuns a outras épocas históricas, e considera que somente o esporte moderno apresenta, ao mesmo tempo, as características relacionadas à secularidade, à igualdade de chances, à especialização de papéis, à racionalidade, à burocracia, à quantificação e ao recorde.

$\mathrm{Na}$ esteira dessas discussões, Elias e Dunning (1992) analisam o esporte a partir do processo civilizatório iniciado na Inglaterra no século XVIII, que está relacionado com o aumento da sensibilidade em relação à violência, e que teria interferido na passagem dos jogos aos esportes. Assim, alguns dos antigos passatempos, como lutas sem regras e embates violentos, se transformariam em esportes e se caracterizariam por "confrontos altamente regulamentados, exigindo esforço físico e competência técnica, caracterizados na sua forma de espetáculo como “desporto'” (ELIAS; DUNNING, 1992, p.46). Nessa perspectiva, os esportes são configurações sociais que oferecem oportunidades para experimentar a violência de modo mimético, como um descontrole controlado.

Um dos "personagens empíricos" que ilustra essa invenção e seus significados no processo civilizatório é o "caçador com sua matilha de cães em busca de raposas". O autor descreve, na configuração social da elite inglesa dos séculos XVIII e XIX, a transformação da caça à raposa de um passatempo a um esporte. O ritual esportivo inglês proibia qualquer participação humana direta na morte da raposa - o que representava "um avanço civilizado" no controle da violência -, cabendo às matilhas treinadas pelos caçadores a função de perseguir e matar apenas as raposas. A violência da perseguição e da morte era vivida de maneira indireta (morte por procuração), resultando numa tensão-excitação 
agradável socialmente aceita, e destacando como protagonista o controle da violência.

Nas últimas três décadas, as artes marciais mistas (MMA), objeto de análise deste estudo, ganharam espaço como modalidade de combate e vieram a ser compreendidas a partir do processo de esportivização (BOTTENBURG; HEILBRON, 2006; SÁNCHEZ-GARCÍA; MALCOLM, 2010; VASQUES; BELTRÃO, 2013). Esses estudos se detiveram às mudanças nas regras da modalidade ocorridas sobretudo nos anos 1990, quando ela foi proibida em locais dos Estados Unidos em decorrência das alegações de violência contida na prática, o que gerou significativos impactos financeiros aos organizadores da modalidade. Em contrapartida, o UFC ${ }^{1}$ modificou a modalidade ao incluir regras que visavam à diminuição da violência nas lutas, e diminuiu a quantidade de violência exposta nos combates, afastando a câmera de imagens sangrentas e evitando textos que poderiam ser considerados demasiados violentos pelo público.

Apesar de tal compreensão esportivizada do MMA, existem características dessa modalidade que a distinguem de outros esportes e de outras modalidades de combate. O estudo de Downey (2014) apresenta a noção de "hiperviolência aparente" para descrever o MMA, que seria um tipo de combate estilizado que usa a violência como espetáculo para atender às expectativas do público. Nessa mesma lógica, Brett (2017) entende que o MMA se desenvolve em quatro categorias: o repulso à violência excessiva, a chatice da ação insuficiente, as práticas suaves palatáveis e a violência estética sublime.

Além do uso da violência como parte do espetáculo, outros dois elementos fundamentais e particulares do MMA, e que serão debatidos ao longo do texto, mostram que há elementos dessa modalidade que não foram explorados. O primeiro é que, ao contrário dos outros esportes, o MMA "tem dono", ou seja, indivíduos que são proprietários da marca. Assim é o UFC, que organiza as regras e os grandes eventos, e assim também são os eventos menores; o que contrasta com a noção de institucionalização, tão cara ao conceito de esporte e que o vincula aos clubes, universidades, federações etc. O outro elemento é o que denominamos "espetáculo acima da vitória", que confronta a concepção tradicional de pertencimento dos torcedores; e que infere na prerrogativa de outros sentidos para a prática, esses opostos à noção de meritocracia.

Não foram encontrados estudos que apresentassem empiricamente e que analisassem tais elementos diferenciadores para a compreensão do MMA em relação à noção de esporte, o que reforça a importância de analisar essa modalidade.

Em vista dessas características distintivas do MMA, cabe questionar: quais as aproximações e distanciamentos do MMA com outros esportes consolidados e com a sua caracterização na sociologia do esporte? Assim, o objetivo deste trabalho foi analisar o MMA a partir daquilo que o distingue dos outros esportes com base no conceito de esportivização proposto por Elias e Dunning. 


\section{PROCEDIMENTOS METODOLÓGICOS}

Este estudo se caracterizou como uma etnografia, ao se aproximar daquelas advindas da antropologia urbana, bem como se identificou como multissituada no sentido de Marcus (2001), que propõe pensá-la como movimento e, para tal, adotouse a postura de seguir os interlocutores. A análise cultural do universo do MMA buscou entender os padrões e significados ali envolvidos, bem como, tal qual afirma Fonseca (1999), trazer dados que se relacionem com a produção acadêmica a fim de proporcionar o elo entre teoria e realidade.

A etnografia foi realizada em uma academia de MMA, na qual um dos pesquisadores frequentou, substancialmente, o treino das $11 \mathrm{~h}$ às $13 \mathrm{~h}$, de setembro de 2014 até outubro de 2015. As aulas contavam com oito a doze lutadores. O pesquisador treinou com os atletas, envolveu-se em conversas, almoçou com a equipe e frequentou os eventos em que alguns deles participaram. Tal interação envolve aquilo que os antropólogos chamam de "observação participante", na qual o pesquisador assume um papel perfeitamente digerível pela sociedade observada a ponto de viabilizar, conforme Oliveira (1996), uma aceitação senão ótima pelos membros daquela sociedade, pelo menos afável de modo que não impeça a necessária interação.

Os dados foram descritos em um diário de campo que, conforme Winkin (1998), tem funções: empírica, de obtenção de informações vindas da observação; reflexiva, que relaciona essas informações com outros trabalhos já realizados; e catártica, que busca a interação do pesquisador com o objeto a partir dos sentimentos, mudanças de concepção, angústias e dúvidas. A partir das observações, oito indivíduos foram convidados para a realização de entrevistas formais. Todos já tinham, ao menos, cinco lutas de MMA. Ademais, oito eventos de MMA, sete deles profissionais, foram acompanhados e registrados.

A análise dos dados resultou em três categorias empírico-analíticas: 1) o "dono do evento", que reflete que no MMA há "donos" que escolhem quem vai lutar; 2) a construção social entre os atores de que o espetáculo - o "show" - é exigido dos atletas, e que tal predicado se torna, por vezes, mais importante do que a vitória; e 3) a "violência como espetáculo", a qual, mesmo sendo mais explícita que em outras práticas de lutas já consolidadas socialmente, ao ser exercida dentro de certos limites civilizatórios, torna-se atrativa e é parte do espetáculo do MMA.

\section{O DONO DO EVENTO}

A configuração do MMA tem características que o distinguem dos esportes como foram historicamente construídos. Uma dessas peculiaridades se refere ao caráter privado das organizações. Enquanto as modalidades são organizadas, de modo geral, por federações que regulamentam a prática e organizam competições, ou então validam aquelas organizadas por clubes, o MMA é regrado sobretudo por uma empresa privada, o UFC. Vale ressaltar que mesmo os eventos de menor porte são propriedade de indivíduos ou empresas, ou seja, têm "donos". 
O dono do evento é, assim, um personagem empírico, na linha daqueles apresentados por Elias ao retratar guerreiros medievais (ELIAS, 1993; 1994), o rei Luís XIV (ELIAS, 2001) e Mozart (ELIAS, 1995). A descrição desse personagem procura dar sentido às suas ações na configuração, de modo a refletir sobre as características, limites e possibilidades de interpretação do MMA como manifestação contemporânea de esporte. Apresentamos, a seguir, alguns relatos de diários de campo.

Ao chegar numa "pesagem" de lutadores, ocorrida em um hotel luxuoso de Porto Alegre, percebia-se um certo clima de tensão. Observavam-se diversos veículos de imprensa à frente da balança. Atrás dela, estavam os atletas com rostos concentrados e visivelmente fracos, já que a maioria deles provavelmente perdera muito peso antes das lutas. O principal processo a que esses atletas recorrem para perder os quilos que ainda faltam para chegarem ao peso da categoria é a desidratação, realizada por minutos, às vezes horas, em uma sauna.

Muitos lutadores passam pela balança; todos alcançam as marcas estipuladas para suas categorias. A torcida e os técnicos vibram com os atletas, que transparecem alegria e alívio. Entretanto, na pesagem de uma das principais lutas do evento, na categoria pena (até $65,7 \mathrm{~kg}$ ), Dieguinho ${ }^{2}$ não consegue "bater o peso".

O primeiro lutador, Carlinhos [...] entra na sala. [...] Ele sobe na balança aos cuidados do 'dono do evento', de seu treinador, do announcer e do treinador do adversário. Ele 'bate o peso'. O announcer diz: 65,6kg. O atleta vibra com sua equipe [...]. Entra o seu adversário, Dieguinho, a expressão dele e da equipe é de preocupação. Os rostos sérios, como se soubessem que algo de não muito bom iria acontecer. [...] Ele sobe na balança. Seu peso é anunciado: $66,2 \mathrm{~kg}$ ( $500 \mathrm{~g}$ acima). Há silêncio na sala, o lutador e seu técnico ficam visivelmente constrangidos com a situação. A equipe adversária fica contrariada, faz sinais de negativo com a cabeça [...].

Agora é a vez de Sérgio [dono do evento] entrar em cena. Ele [...] faz uma intervenção interessante: 'O Dieguinho não bateu o peso, não foi profissional. Agora depende do adversário aceitar lutar com ele ou não. Se o Carlinhos não aceitar, só ele recebe a bolsa e não tem luta. O Dieguinho não recebe nada. Se o Carlinhos aceitar, tem luta, mas o adversário vai perder $20 \%$ da bolsa. No MMA, não tem mais espaço pra amador, tem que ser profissional'. O 'dono do evento' pergunta ao atleta se ele ainda aceita a luta, mesmo sem o adversário bater o peso. Carlinhos aceita. Há vibração na sala e gritos de 'guerreiro'. Todos aplaudem e Sérgio dá o recado: 'Não bateu o peso, vê se 'dá o show' amanhã, se não, não luta mais no meu evento'. Fico pensando nessa flexibilização das regras: o atleta não bate o peso, mas luta com a concordância do adversário. Sérgio resolve a situação como lhe apraz. Ele pode. É o ‘dono do evento'. (D.C. 20/12/2014)

O dono do evento é um personagem importante, pois ele altera a configuração. Ao mesmo tempo em que pune o atleta tirando $20 \%$ de sua bolsa, ele pressiona-o para "dar o show" no dia seguinte. Ademais, chama a atenção para que essa luta atraia os espectadores. Ele constrói uma espécie de "mocinho" (que aceitou a luta, mesmo prejudicado) contra "bandido" (que não foi profissional), estratégia de mobilização do público amplamente utilizada no mundo das lutas. Há registros de desafios, desde a década de 1960, entre boxeadores que criavam certa "inimizade" antes das lutas (REMINICK, 2000), num clima que mistura elementos de "esporte" e "briga", criando 
uma agradável tensão-excitação (ELIAS; DUNNING, 1992) que estimula a presença do público nos eventos.

Sérgio sabe o que faz. Ele lutava vale-tudo em uma equipe famosa dos anos 1990, porém teve mais sucesso como promotor de evento. Há relatos (GRACIE, 2008; $A W I, 2012)$ que mostram as estratégias publicitárias que ele utiliza para promover as lutas. Ele criou um evento/marca de MMA no Brasil que é reconhecido no mundo das lutas como uma possibilidade de ascensão para eventos maiores. Durante a pesagem, percebo o protagonismo desse personagem.

A função social desse personagem na configuração é fundamental, na medida em que cabe a ele a decisão sobre esses afrouxamentos das regras, e também reveladora, já que desvelou critérios para a seleção dos atletas que possibilitaram entender a importância do espetáculo naquele contexto. Ainda, a atuação do dono do evento contrasta com a institucionalização dos esportes, historicamente acoplada em federações. Apesar de existirem federações de MMA, elas foram criadas depois do UFC, como uma estratégia de aproximação com a organização esportiva, porém não cabe a elas a organização das regras da modalidade e das competições.

Para Elias e Dunning (1992), a institucionalização é uma "terceirização" da regulação esportiva. A partir da diferenciação social ocorrida na Inglaterra pósindustrial, os grupos não são mais responsáveis pelo estabelecimento do controle da violência e "terceirizam-na" para o Estado, que tem o monopólio desse controle. A institucionalização esportiva representa essa instância capaz de regular e determinar o padrão ético do esporte. Como os dados mostram, de forma bastante diferente do que ocorre no mundo esportivo institucionalizado, na configuração do MMA cabe ao dono do evento definir quem vai lutar e, quando necessário, ele tem o poder de flexibilizar as regras para que o evento seja um espetáculo de acordo com o esperado.

\section{ESPETÁCULO ACIMA DA VITÓRIA}

A segunda categoria de análise busca mostrar como o espetáculo, o "dar show", se torna tão ou mais importante que a vitória no MMA. Após a pesagem dos atletas, o dono do evento instrui, aos gritos, como os atletas devem se comportar. Ele decidiu que haveria espetáculo e exigia "porrada".

Galera, seguinte: amanhã é guerra! Não quero ver ninguém 'jogando na retranca', quero ver a 'porrada comer'. Se perder e der show, vai lutar de novo no evento! Se ganhar 'amorcegando's, nunca mais vai ser chamado para lutar. Porrada! Aqui, o filho chora e a mãe não ouve. (D.C. 20/12/2014)

A fala parece ter efeito nos lutadores. Suas expressões ficam sérias, seus rostos se concentram e na plateia um silêncio se instala. Os atletas juntam-se às suas equipes e muitos tiram fotos com Sérgio. Para essas, ele sorri, pois será "postada" em outro contexto. Não há ato desinteressado. As ações do dono do evento têm interesse de atrair o público ao apresentar o evento como um show, um espetáculo em que as lutas se propõem não somente a definir o vencedor, o campeão, mas

3 "Amorcegar" é um termo nativo que representa a ação do lutador proteger-se demasiadamente. 
também são espaços para a profusão de uma tensão-excitação agradável construída no uso da violência como atrativo que, porém, esteja dentro de limites socialmente aceitos na configuração esportiva.

A atuação do dono do evento ditando as regras e os modos de agir dos atletas suscitou refletir sobre a vitória-derrota no MMA. A vitória é o elemento mais importante nas lutas? O elemento principal em um combate não seria "dar show"? Assim, perguntamos aos atletas nas entrevistas: "Tu achas mais importante no MMA ganhar as lutas ou fazer boas lutas?". As respostas permitiram analisar o dilema com maior clareza.

Celso: Ganhar, todo mundo quer. Ninguém quer perder. Mas eu acho mais interessante tu fazeres uma boa luta. [...] O mundo do MMA virou um negócio de dinheiro, então tem muito bom lutador, bom atleta, que não é bom nocauteador, mas ele leva um público fora de série para ver ele lutar. Então, eu acho muito interessante tu fazeres uma boa luta porque, tu vencendo ou não, tu vais ter a oportunidade de lutar novamente. Agora, fez uma luta ruim, ganhou, tudo bem. É bom. Mas eu vejo que o pessoal quer show desde a parte de um movimento impossível até a tua vitória.

Fernando: Com certeza, fazer o espetáculo é mais importante que ganhar. Porque às vezes tu lutas e, pô, tu tens uma vitória fácil, de repente não consegues demonstrar toda a tua técnica. Agora se tu pegares um adversário de nível e puderes demonstrar toda tua técnica, todo teu trabalho que tu treinaste pra chegar até ali é bem melhor do que ganhar. Mesmo perdendo. Eu prefiro perder e dar um show do que ganhar dum morto.

Diego: Hoje em dia, os promotores do evento querem não só a vitória, eles querem que tu faças uma boa luta, então tem eventos que priorizam uma boa luta pra tu te manteres neles e tem eventos que cobram resultados, o cartel do atleta. Então, eu acho que são duas estradas que levam no mesmo caminho. [...] Acho que tu ganhares e fazer uma boa luta são determinantes para tu teres uma carreira de sucesso. (grifos dos autores)

Os três lutadores sinalizaram a importância de fazer boas lutas e dar bons espetáculos para o sucesso no MMA. Quando o dono do evento os orienta a "não jogar na retranca", isso é entendido pelos atletas. O dono do evento pautou a situação em "lutar bem" (ou não luta) e ninguém colocou isso em dúvida. Também não foi questionada a sua autoridade. Proteger-se demais e não agredir o adversário é "amorcegar" a luta. Deve-se "ir para cima", sem muito temor a levar um nocaute. Isso faz com que os atletas sejam recontratados pelos eventos. Ao mesmo tempo, se não der show, o atleta pode não mais ser contratado.

No futebol, por exemplo, é possível afirmar que a tensão-excitação também está no "jogo bonito", mas importa mais vencer, tanto que a torcida critica o time que "se arrisca" em atacar tendo o placar favorável. De qualquer forma, jogar bem, mas perder não ajuda muito, pois a instituição se pauta pelos resultados, e nenhum clube avança na competição por jogar bem, só progride ganhando. E desde que ganhe, avança, mesmo que ganhe "jogando feio". Nessa situação, não há quem possa colocar isso em dúvida e decidir por outros critérios.

Os argumentos relevam a importância de "dar show" frente à vitória. Celso inclui o elemento da imprevisibilidade do confronto quando cita "um movimento 
impossível". Na dinâmica interna do MMA, a imprevisibilidade é um elemento importante para o equilíbrio de tensão-excitação, que se caracteriza na variabilidade dos golpes e nas muitas possibilidades de ocorrer um nocaute, o que dificulta prever o vencedor anteriormente aos confrontos. Ainda, Fernando afirma preferir "perder e dar um show do que ganhar dum morto". Não se trata de uma preferência individual, mas sim de uma configuração social, já que se o atleta não "der show", mesmo ganhando ele vai perdendo espaço naquele contexto.

A importância de o atleta lutar com o intuito de agradar ao público também foi observada presencialmente em um evento do UFC, onde observaram-se vaias sendo entoadas quando as lutas iam para o chão ou havia pouca "trocação"4. Nesses momentos, ouviam-se gritos de "luta", "porrada", "não amorcega". O público quer ação, elemento importante na configuração. É possível afirmar que o público no MMA não costuma torcer para nenhum atleta em particular, e isso foi percebido também nesse evento. Nessa lógica, os pertencimentos das "torcidas" no MMA ocorrem de modo distinto dos esportes tradicionais, como o futebol, por exemplo, nos quais os pertencimentos clubísticos e nacionais ocupam lugar privilegiado nas narrativas e na construção de identidades. Os pertencimentos identitários são parte estruturante do esporte moderno, como destacado por Bourdieu (1983) ao retratar o associativismo esportivo, assim como por Hobsbawm (2012) ao analisar a proliferação de identidades nacionais a partir do esporte. No MMA os pertencimentos não se dão de modo a torcer por um atleta em particular, o que pode ser ratificado nos dados de campo descritos em seguida.

Além da discussão sobre os pertencimentos, o elemento central é que a derrota ou vitória fica em segundo plano para o público. Os donos de evento e os atletas sabem disso. Mas quando há outros interesses em jogo? Quando há disputa de cinturão e os atletas mais querem ganhar que "dar show"? Nesse caso, há tensão na configuração. Um exemplo ocorreu na disputa de cinturão entre Márcio "Pedra" e Alex "Bomba".

[...] 'Pedra' e 'Bomba', dois lutadores bem conhecidos do público. [...] A torcida vibra com os dois, [...] parece que não há torcida por um deles. A luta começa e é visível a falta de ação dos dois lutadores. Eles estudamse e pouco agridem um ao outro. [...] a torcida começa a vaiar a luta. Os gritos são ostensivos e parecem ter efeito sobre a luta. Pedra entra com jab e cruzado e acerta a cabeça de Bomba de raspão. Bomba consegue derrubar Pedra e o round acaba. Apesar da ação final, a torcida vaia [...]. $O$ segundo e terceiro rounds obedecem a mesma dinâmica do primeiro. [...] A torcida vaia o tempo inteiro, mas os lutadores dão a impressão de não quererem se expor para a possibilidade de um nocaute e a consequente perda do cinturão. [...] O juiz [...] anuncia: '[...] o campeão do cinturão [...] é... Márcio Pedra'. O lutador comemora, mas a torcida vaia o campeão. Ele recebe o cinturão do dono do evento e dá entrevista [...]: 'Galera, eu peço desculpas se a luta não agradou. Mas é que isso aqui vale bem mais que o cinturão. Eu luto pela minha família, pelo meu filho e quero dar uma condição de vida melhor para eles. Eu não poderia me expor muito porque eu queria muito esse título. Muito obrigado por vocês terem vindo aqui e por terem assistido a minha luta. Eu amo vocês'. A torcida, que vaiava o lutador alguns minutos antes, começa a aplaudi-lo. Parece que seus argumentos foram convincentes. (D.C. 12/09/2015, grifos dos autores)

4 Termo nativo que designa uma luta na qual os lutadores trocam golpes, como socos e chutes. 
A torcida vaiar o campeão e o vencedor se desculpar pela forma que a vitória ocorreu não são atitudes comuns no esporte, mas ocorrem no MMA. A "luta dura" é um objetivo do público, e alguns lutadores sabem agir quando esse propósito não é alcançado. O sofrimento do treinamento, a família e a busca por melhor "condição de vida" são argumentos que convencem. O equilíbrio de tensões é mantido. A configuração do MMA constrói, assim como Wacquant (2002) relata sobre o gym, esse ideal de mobilidade social.

Os argumentos e cenas mostram que os atletas aprenderam que no MMA não é suficiente ganhar as lutas, mas que é preciso lutar de acordo com as regras do jogo espetacularizado: "dar show", "fazer uma boa luta", "mostrar toda a técnica", "ir pra cima", "luta dura", "porrada". Nesse jogo, são exigidos elementos produzidos com o intuito de produzir uma tensão-excitação agradável no público, uma forma de catarse ${ }^{5}$, e que têm relação com a espetacularização da violência. Isso parece acontecer também em outras lutas, mas no MMA essa condição é determinante da continuação (ou não) do atleta na carreira.

O estudo de Brett (2017) indica a "chatice da ação insuficiente" como elemento estruturante do MMA, ou seja, a ação dos atletas no combate deve ser suficiente para entreter os espectadores. No MMA, o "chato" é determinante para conduzir os modos de agir. O aparecimento desse elemento desafia a lógica meritocrática e se põe em contraste com as noções de resultado, vitória, progresso e recorde (GUTTMANN, 1978), centrais ao esporte. É fundamental que os modos de lutar atinjam alto nível de tensão-excitação nos espectadores. Desse modo, o dono do evento e o espetáculo acima da vitória se mostram como dois elementos fundamentais na configuração do MMA e que põem em tensão a noção de esporte da forma como ele tem sido descrito na sociologia.

O resultado do combate e a busca pela vitória são desestabilizados quando o espetáculo e o "dar show" assumem lugar preponderante na configuração social e na dinâmica interna da luta. O atleta que perde, mas não "amorcega", continua com chances naquele universo. Bastos (2006) mostrou, com a noção de "o corre", que no skate o capital esportivo não era o único determinante para o sucesso, mas que saber o modus operandi daquele universo era fundamental para conseguir patrocínio. É compreensível que as habilidades necessárias para ter sucesso no esporte não se resumam às competências esportivas, mas se ampliem para dimensões sociais, educacionais e de acesso. No entanto, o diferencial no MMAé que, para ter sucesso, mesmo que vencer também importe, não é fundamental ganhar a luta, mas sim "dar show".

\section{A VIOLÊNCIA ESPETACULARIZADA}

A violência é parte do espetáculo do MMA. Nesse sentido, os lutadores são forjados para além das estratégias para vencer, são construídos para que as suas ações transmitam elementos de violência espetacularizada. Em acordo com Mariante Neto, Vasques e Stigger (2021), a imagem dos lutadores de MMA não é construída

5 Para Elias e Dunning (1992), catarse se refere à transformação das emoções a partir da tensão-excitação agradável provocada pelo esporte. 
apenas "entre as grades", mas uma série de estratégias são utilizadas para produzir a imagem de um lutador. Este tópico começa com uma cena que mostra a construção da violência como parte do espetáculo.

Com o crescimento do MMA, as produtoras de eventos aproximaram-se para produzir imagens que constroem a antessala dos combates. Os eventos têm perfis nas redes sociais que mostram lutas e treinamentos; lutadores mostram suas rotinas em perfis no Facebook, Twitter e Instagram. As postagens parecem representar o cotidiano, mas têm intencionalidades vinculadas às construções de imagem feitas pelas produtoras. $\mathrm{Na}$ academia presenciamos uma filmagem. Antônio, atleta da equipe, tinha luta marcada, e Carlos, produtor do vídeo, orientava como ele deveria agir na gravação.

O treinador [...] começa a dar algumas sequências para Antônio fazer. São variações de chutes e socos [...]. Carlos orienta: 'Bate com mais vontade, vamos mostrar pra ele que tu vais arrancar a cabeça dele.'

É a hora da gravação do vídeo em que o lutador 'desafia' seu adversário. [...] o produtor [...] orienta: 'Tem que fazer cara de mau. [...] quando eu der o sinal, tu falas: Careca [oponente], pode esperar, esse cinturão vai ser meu, tu não vais conseguir tirar ele de mim.' [...] Antônio não consegue decorar a frase e Carlos repete. A gravação recomeça, Antônio novamente não consegue dizer o combinado e a gravação para. [...] Finalmente, o atleta consegue falar as palavras de desafio para seu adversário.

[...] à tarde, procuro o vídeo na página da produtora do Facebook. Ele tem cerca de dois minutos, mostra alguns fragmentos de luta do atleta, imagens do treino da manhã e a fala final. [...] As imagens mostram um lutador aguerrido, habilidoso e quase imbatível. Suas palavras parecem ameaçadoras, sua voz é firme e o desafio parece quase pessoal em relação ao outro atleta. As fragilidades desapareceram, os erros não foram mostrados, Antônio parece quase como um superatleta, um homem de ferro capaz de nocautear quem apareça pela frente. Enfim, acho que o vídeo foi bem produzido. (D.C. 12/12/2014)

O vídeo demonstra mecanismos intencionais para transformar a luta em um desafio. Antônio não conhecia seu adversário nem havia rivalidade entre eles. Para que os eventos aconteçam, o público deve se interessar pelas lutas, e elementos de violência ("arrancar a cabeça", "desafio", "cara de mau", "aguerrido", "imbatível", "ameaçadoras", "voz firme") são elencados de forma a causar tensão-excitação nos espectadores.

Outra cena do evento de pesagem mostra como elementos de desafio, ameaça e simbolicamente violentos são empregados.

Os lutadores posicionam-se em frente ao [...] banner grande com as principais marcas que apoiam e patrocinam o evento. Todos fazem a famosa 'cara de mau' dos lutadores. Alguns fecham o punho e colocam à frente do rosto em uma posição de 'guarda'. Outros apenas olham para as câmeras de cima para baixo. Nenhum sorriso. Sérgio posiciona-se na frente dos atletas. Sua expressão também não demonstra cordialidade. A sensação é que uma guerra está prestes a acontecer. (D.C. 20/12/2014)

Essa cena nada tem de violência descontrolada, tendo em vista a intencionalidade em se criar tal ambiente. A "cara de mau" e o "clima de guerra" são ações produzidas recorrentemente também em outras lutas como, por exemplo, no 
boxe. No entanto, o MMA é recorrentemente acusado de ser "mais violento" do que outras modalidades, especialmente por atores de outras modalidades de combate, inclusive do boxe. Exemplo disso é a afirmação do ex-campeão mundial Éder Jofre de que as artes marciais mistas são uma "volta à barbárie" (MARIANTE NETO, 2016). Nesse sentido, a violência do MMA não estaria somente nas intencionalidades da sua produção para o espetáculo, mas também como categoria de acusação (CURI, 2017).

As duas cenas mostram elementos construídos para transmitir elementos simbolicamente violentos ("guerra", "cara de mau", "ameaçador", "arrancar a cabeça") como parte do espetáculo. Esses dados também corroboram a noção de hiperviolência aparente do MMA (DOWNEY, 2014) e com a categoria de violência estética sublime (BRETT, 2017), as quais indicam o uso desses elementos no MMA como forma de atrair o público.

Em diálogo com o processo de esportivização proposto por Elias e Dunning (1992), que mostra a diminuição da violência nos combates como um elemento do processo civilizador, as cenas aqui apresentadas indicam que no MMA a violência é elencada dentro de certos padrões civilizatórios, eventualmente não tão aceitos pela sociedade "em geral", para aumentar o nível de tensão-excitação dos combates.

Isso faz-nos refletir sobre as rupturas relacionadas à violência a partir da não linearidade do processo civilizador. Nesse sentido, outros elementos na configuração do MMA (os eventos privados e o espetáculo) fazem com que outras tensões relacionadas à violência sejam redirecionadas. O que poderíamos chamar de "alargamento da violência" não é novidade na teoria proposta. Se Elias e Dunning nos mostram que a morte nas lutas era elemento constitutivo e uma "violência" aceita na Grécia Antiga, hoje, por vivermos em uma sociedade espetacularizada e mais complexa, esse "alargamento" parece produzir uma tensão-excitação agradável, cooptando público e telespectadores. O que propomos, assim, é que o MMA, apesar de esportivizado, produz violência com sentido de espetáculo, e que, por mais que haja um discurso de reprovação, os usos dessa violência auxiliaram a tornar o esporte popular e a cooptar muitos adeptos.

\section{CONCLUSÕES}

Neste trabalho objetivou-se analisar o MMA a partir daquilo que o distingue de outros esportes com base no conceito de esportivização proposto por Elias e Dunning. Para tanto, elegeu-se como procedimento metodológico a etnografia.

A primeira categoria desenvolvida foi o "dono do evento". A partir da construção de um personagem empírico com papel central dentro da configuração, já que ele modifica regras conforme o seu interesse, refletiu-se sobre a institucionalização que no MMA, diferentemente de outras modalidades, está centrada em uma empresa privada e em eventos com "donos".

O "espetáculo além da vitória", segunda categoria analítica deste estudo, apresenta um relativo desacordo do MMA frente ao resultado esportivo. A tensãoexcitação agradável provocada pelo espetáculo e materializada em "disputas duras" 
se sobrepunha à vitória, fazendo com que atletas se manifestassem no sentido de deslocar, em nível de importância em uma luta, o espetáculo para uma posição acima da vitória/resultado. Além de relativizar predicados esportivos como resultado, vitória, progresso e recorde, essa categoria refletiu sobre o "torcer" no MMA, dialogando com a noção de pertencimento, que é instituidora do esporte moderno.

A terceira categoria se pautou por compreender que a violência é utilizada como parte do espetáculo no MMA. Fez-se, assim, uma análise de espaços ocupados pela violência nesse esporte, do seu uso dentro de limites civilizatórios e do "alargamento de uma violência" que produz sentido de espetáculo a fim de produzir uma tensãoexcitação agradável, o que infere um novo padrão ético dentro do esporte.

Esses elementos devem ser levados em consideração ao se utilizar das análises da sociologia clássica do esporte, precisamente porque tais análises acabam por ter, em parte, características do seu tempo, o que é típico dos estudos históricos e sociais. Assim, é questionável enquadrar dentro de teorias sociológicas a compreensão de todos os elementos do MMA, ou do esporte atual.

Desse modo, cabe perguntar: onde o MMA se insere hoje? Os dados indicam que o esporte contemporâneo exige uma discussão que relativize alguns dos conceitos clássicos da sociologia do esporte. Tendo em vista que a sociedade passa por transformações profundas em termos de comunicação e de costumes, entendese que tais mudanças também se aplicam à análise do esporte.

Para concluir e contribuir com a discussão sociológica do esporte, afirmamos que o conceito de esportivização (ELIAS; DUNNING, 1992) apresenta limites na análise do MMA. Se os autores analisam as mudanças da lógica interna relacionadas a um repúdio em relação à violência, nós conjeturamos que essa violência, atualmente, também é espetacularizada. Se os autores alegam que as regras se transformam a partir de restrições de comportamentos, nós concluímos que estas regras também estão a serviço do espetáculo. Se os autores apresentam um processo de esportivização relacionado à industrialização da sociedade inglesa, podemos concluir que, na sociedade atual, estamos vivendo uma "segunda esportivização". Esta relacionada ao espetáculo, à mídia e aos eventos privados.

\section{REFERÊNCIAS}

AWI, Fellipe. Filho teu não foge à luta: como os lutadores brasileiros transformaram o MMA em um fenômeno mundial. Rio de Janeiro: Intrínseca, 2012.

BASTOS, Billy Graeff. Estilo de vida e trajetórias sociais de skatistas: da "vizinhança" ao "corre". Dissertação (Mestrado em Ciências do Movimento Humano) - Escola de Educação Física, Fisioterapia e Dança, Universidade Federal do Rio Grande do Sul, Porto Alegre, 2006.

BOTTENBURG, Maarten van ; HEILBRON, Johan. De-sportization of fighting contests: the origin and dynamics of No Holds Barred events and the theory of sportivization. International Review for the Sociology of Sport, v. 41, n. 3-4, p. 259-282, 2006. Disponível em http:// dspace.library.uu.nl/bitstream/handle/1874/305739/Van_Bottenburg_Heilbron_2006_De sportization_of_fighting_contests.pdf?sequence=1\&isAllowed=y Acesso em: 22 fev. 2021. 
BOURDIEU, Pierre. Como é possível ser esportista? In: BOURDIEU, Pierre. Questões de sociologia. Rio de Janeiro: Marco Zero, 1983. p. 136-153.

BOURDIEU, Pierre. Os Jogos Olímpicos. In: BOURDIEU, Pierre. Sobre a televisão. Rio de Janeiro: Zahar, 1997. p. 123-127.

BOURDIEU, Pierre. Programa para uma Sociologia do Esporte. In: BOURDIEU, Pierre. Coisas ditas. São Paulo: Brasiliense, 1990. p. 207-220.

BRETT, Gordon. Reframing the 'violence' of mixed martial arts: the 'art' of thefight. Poetics, n.62, p.15-28, 2017. Disponível em: https://www.sciencedirect.com/science/article/abs/pii/ S0304422X1630136X?via\%3Dihub. Acesso em: 30 Sept. 2020.

CURI, Martin. Violência como categoria de acusação nos discursos de torcedores de futebol no Rio de Janeiro. Policromias, v. 2, n. 1, p .28-52, 2017. Disponível em: https://revistas.ufrj.br/index.php/policromias/article/view/12526 Acesso em: 01 out. 2020.

DOWNEY, Greg. 'As Real As It Gets!': Producing hyperviolence in mixed martial arts. JOMEC Journal. v.5, 2014. Disponível em: https://jomec.cardiffuniversitypress.org/articles/ abstract/10.18573/j.2014.10268/ Acesso em: 30 set. 2020.

ELIAS, Norbert. Mozart: sociologia de um gênio. Rio de Janeiro: Jorge Zahar, 1995.

ELIAS, Norbert. O processo civilizador. Rio de Janeiro: Jorge Zahar, 1993. v. 2

ELIAS, Norbert. O processo civilizador. Rio de Janeiro: Jorge Zahar, 1994.

ELIAS, Norbert. A sociedade de corte: investigação sobre a sociologia da realeza e da aristocracia de corte. Rio de Janeiro: Jorge Zahar, 2001.

ELIAS, Norbert; DUNNING, Eric. A busca da excitação. Lisboa: Difel, 1992.

FONSECA, Cláudia. Quando cada caso não é um caso: pesquisa etnográfica e educação. Revista Brasileira de Educação, n. 10, p. 58-78, jan./abr. 1999. Disponível em: https://anped.org.br/sites/default/files/rbe/files/rbe 10.pdf . Acesso em: 30 set. 2020.

GRACIE, Reila. Carlos Gracie: o criador de uma dinastia. Rio de Janeiro: Record, 2008.

GUTTMANN, Allen. From ritual to record: the nature of modern sports. New York: Columbia University, 1978.

HOBSBAWM, Eric. A Produção em Massa das Tradições: Europa, 1870 a 1914. In: HOBSBAWM, Eric; RANGER, Terence (Org.). A invenção das tradições. Rio de Janeiro: Nova Fronteira, 2012. p. 327-379.

MARCUS, George. Etnografia en/del sistema mundo: o surgimento de la etnografia multilocal. Alteridades, v. 11, n. 22, p. 111-127, jul./dez. 2001. Disponível em: https://www. redalyc.org/pdf/747/74702209.pdf . Acesso em: 30 set. 2020.

MARIANTE NETO, Flávio Py. Jabs, diretos, low kicks e duble lags no processo civilizador: uma leitura elisiana das artes marciais mistas. Tese (Doutorado em Ciências do Movimento Humano) - Programa de Pós-Graduação em Ciências do Movimento Humano, Universidade Federal do Rio Grande do Sul. Porto Alegre, 2016. Disponível em: https:// lume.ufrgs.br/handle/10183/153321 Acesso em: 22 fev. 2021. 
MARIANTE NETO, Flávio Py; VASQUES, Daniel Giordani; STIGGER, Marco Paulo. A construção televisiva do MMA: o programa TUF Brasil e o processo de humanização do lutador. Revista Brasileira de Ciências do Esporte, v. 43, e002820, 2021. Disponível em http://www.scielo.br/scielo.php?script=sci arttext\&pid=S0101-32892021000100201\&lng=pt\& nrm=iso. Acesso em: 26 abr. 2021.

OLIVEIRA, Roberto Cardoso de. O trabalho do antropólogo: olhar, ouvir, escrever. Revista de Antropologia. v.39, n.1, p.13-37, 1996. Disponível em: https://www.jstor.org/ stable/41616179 Acesso em: 30 set. 2020.

REMINICK, David. O rei do mundo: Muhammad Ali e a ascensão de um herói americano. São Paulo: Companhia das Letras, 2000.

SÁNCHEZ-GARCÍA, Raul; MALCOLM, Dominic. Decivilizing, civilizing or informalizing? The international development of Mixed Martial Arts. International Review for the Sociology of Sport, v.45, n.1, p.39-58, 2010. Disponível em: https://journals.sagepub.com/ doi/10.1177/1012690209352392. Acesso em: 22 fev. 2021.

VASQUES, Daniel Giordani; BELTRÃO, José Arlen. MMA e Educação Física escolar: a luta vai começar. Movimento, v.19, n.4, p.289-308, 2013. Disponível em: https://seer.ufrgs.br/ Movimento/article/view/37713 . Acesso em: 30 set. 2020.

WACQUANT, Loïc. Corpo e alma: notas etnográficas de um aprendiz de boxe. Rio de Janeiro: Relume Dumará, 2002.

WINKIN, Yves. Descer ao campo. In: WINKIN, Yves. A nova comunicação: da teoria ao trabalho de campo. Campinas: Papirus, 1998. p.129-145. 
Abstract: The characterization of modern sport lists elements that distinguish it from other bodily practices. Mixed Martial Arts (MMA) are often understood as a sportized modality based on changes aimed at regulating and reducing violence. This study analyzed MMA based on what distinguishes it from other sports based on the concept of sportization proposed by Elias and Dunning. The ethnographic methodology employed participant observation in an MMA academy and in fighting events, as well as field diaries and interviews. Three empirical-analytical categories were built to analyze elements of MMA - the "owner of the event," show rather than victory, and violence as a show - which suggest debates with the notions of victory, institutionalization, belonging and violence. The importance to broaden the concept of sport to understand MMA is underscored.

Keywords: Sports. Violence. Institutionalization. Sociology.

Resumen: La caracterización del deporte moderno tiene elementos que lo distinguen de otras prácticas corporales. Las artes marciales mixtas (MMA) suelen entenderse como una modalidad deportizada a partir de cambios destinados a regular y reducir la violencia. Este estudio tuvo como objetivo analizar el MMA a partir de aquello que lo distingue de otros deportes y tuvo como base el concepto de "deportización" propuesto por Elias y Dunning. La metodología, etnográfica, utilizó la observación participante en un gimnasio de MMA y en eventos de lucha, la producción de diarios de campo y entrevistas. Se construyeron tres categorías empírico-analíticas para analizar elementos del MMA (el "dueño del evento", el espectáculo por encima de la victoria y la violencia como espectáculo), las que sugieren debates sobre las nociones de victoria, institucionalización, pertenencia y violencia. Se señala la importancia de ampliar el concepto de deporte para comprender el MMA.

Palabras clave: Deportes. Violencia. Institucionalización. Sociología. 


\section{LICENÇA DE USO}

Este é um artigo publicado em acesso aberto (Open Access) sob a licença Creative Commons Atribuição 4.0 Internacional (CC BY 4.0), que permite uso, distribuição e reprodução em qualquer meio, desde que o trabalho original seja corretamente citado. Mais informações em: http://creativecommons.org/licenses/by/4.0

\section{CONFLITO DE INTERESSES}

Os autores declararam que não existe nenhum conflito de interesses neste trabalho.

\section{CONTRIBUIÇÕES AUTORAIS}

Flávio Py Mariante Neto: Autor do projeto de pesquisa. Escrita e análise do texto. Revisão.

Daniel Giordani Vasques: Escrita e análise do texto. Revisão.

Marco Paulo Stigger: Orientação do trabalho. Escrita e análise do texto. Revisão

\section{FINANCIAMENTO}

O presente trabalho foi realizado com apoio da Coordenação de Aperfeiçoamento de Pessoal de Nível Superior - Brasil (CAPES) - Código de Financiamento 001. "This study was financed in part by the Coordenação de Aperfeiçoamento de Pessoal de Nível Superior - Brasil (CAPES) - Finance Code 001"

\section{ÉTICA DE PESQUISA}

O projeto de pesquisa seguiu o Guia de Integridade em Pesquisa Científica da Universidade Federal do Rio Grande do Sul e as Resoluções 466/12 e 510/2016 do Conselho Nacional de Saúde do Brasil.

\section{COMO REFERENCIAR}

MARIANTE NETO, Flávio Py; VASQUES, Daniel Giordani; STIGGER, Marco Paulo. "Se perder e der show, vai lutar de novo!" MMA e o conceito de esporte.

Movimento (Porto Alegre), v.27, p.e27030, jan./dez. 2021. Disponível em: https:// seer.ufrgs.br/Movimento/article/view/108259. Acesso em: [dia] [mês abreviado]. [ano]. DOI: https://doi.org/10.22456/1982-8918.108259

\section{RESPONSABILIDADE EDITORIAL}

Alex Branco Fraga*, Elisandro Schultz Wittizorecki ${ }^{*}$, Humberto Cesaro**, Mauro Myskiw* $^{*}$ Raquel da Silveira*

*Universidade Federal do Rio Grande do Sul, Escola de Educação Física, Fisioterapia e Dança, Porto Alegre, RS, Brasil.

${ }^{* *}$ Instituto Federal Catarinense (IFC). Departamento de Desenvolvimento Educacional, Luzerna/SC. 